\title{
Diversity and antimicrobial susceptibility profiling of staphylococci isolated from bovine mastitis cases and close human contacts
}

\author{
T. Schmidt, ${ }^{*} \dagger^{1}$ M. M. Kock, ${ }^{*} \ddagger$ and M. M. Ehlers ${ }^{*} \ddagger$ \\ *Department of Medical Microbiology, University of Pretoria, Pretoria 0001, South Africa \\ †Allerton Provincial Veterinary Laboratory, KwaZulu-Natal Department of Agriculture and Rural Development, Cascades 3202, South Africa \\ $\ddagger$ Tshwane Academic Division, National Health Laboratory Service, Pretoria 0001, South Africa
}

\begin{abstract}
The objectives of this study were to examine the diversity of Staphylococcus spp. recovered from bovine intramammary infections and humans working in close contact with the animals and to evaluate the susceptibility of the staphylococcal isolates to different antimicrobials. A total of 3,387 milk samples and 79 human nasal swabs were collected from 13 sampling sites in the KwaZulu-Natal province of South Africa. In total, 146 Staph. aureus isolates and 102 coagulase-negative staphylococci (CNS) were recovered from clinical and subclinical milk samples. Staphylococcus aureus was isolated from $12(15.2 \%)$ of the human nasal swabs and 95 representative CNS were recovered for further characterization. The CNS were identified using multiplexPCR assays, matrix-assisted laser desorption/ionization time-of-flight mass spectrometry (MALDI-TOF MS), and tuf gene sequencing. Seven Staphylococcus spp. were identified among the CNS of bovine origin, with Staph. chromogenes (78.4\%) predominating. The predominant CNS species recovered from the human nasal swabs was Staph. epidermidis (80\%) followed by Staph. chromogenes (6.3\%). The antimicrobial susceptibility of all staphylococcal isolates was evaluated using disk diffusion and was supplemented by screening for specific antimicrobial resistance genes. Ninety-eight (67.1\%) Staph. aureus isolates of bovine origin were pansusceptible; $39(26.7 \%)$ isolates were resistant to a single class, and $7(4.8 \%)$ isolates were resistant to 2 classes of antimicrobials. Two Staph. aureus (1.4\%) isolates were multidrug-resistant. Resistance to penicillin was common, with $28.8 \%$ of the bovine and $75 \%$ of the human Staph. aureus isolates exhibiting resistance. A similar observation was made with the CNS, where $37.3 \%$ of the bovine and $89.5 \%$ of the human isolates were resistant to penicillin. Multidrug-resistance was common among the human CNS, with $39 \%$ of the isolates exhibiting resistance to 3 or more classes of
\end{abstract}

Received April 16, 2015.

Accepted June 8, 2015.

${ }^{1}$ Corresponding author: Tracy.Schmidt@kzndard.gov.za antimicrobials. The antimicrobial susceptibility results suggest that resistance among staphylococci causing bovine intramammary infections in South Africa is uncommon and not a significant cause for concern. In contrast, antimicrobial resistance was frequently observed in staphylococcal isolates of human origin, highlighting a possible reservoir of resistance genes. Continued monitoring of staphylococcal isolates is warranted to monitor changes in the susceptibility of isolates to different classes of antimicrobials.

Key words: Staphylococcus spp., bovine mastitis, antimicrobial resistance, close human contact

\section{INTRODUCTION}

Bovine mastitis, or inflammation of the mammary gland, is one of the most common and economically important diseases affecting the dairy industry worldwide (Barkema et al., 2006). Mastitis primarily occurs in response to microbial infections, although chemical, physical, or traumatic factors may also lead to inflammation. A variety of bacteria have been implicated in bovine IMI (Gentilini et al., 2000), with staphylococci being considered one of the most significant and prevalent groups (Pyörälä et al., 2011).

Staphylococcus aureus is a contagious udder pathogen that readily spreads between cows at milking (Akineden et al., 2001). The main source of the bacterium is milk from infected quarters, with milking machine teat liners playing a significant role in the transmission of the bacteria among cows and mammary quarters (Zadoks et al., 2002). It is imperative that infected cows are promptly identified so that appropriate control measures can be implemented to curb bacterial transmission (Barkema et al., 2006). Other Staphylococcus spp., the so-called CNS, have traditionally been regarded as opportunistic pathogens of minor importance. This perception has arisen because mastitis caused by CNS is very mild and usually remains subclinical (Tenhagen et al., 2006). However, the significance of the CNS is being reassessed because, in many countries including South Africa, CNS have become the most common bacteria isolated from bovine IMI (Petzer et al., 2009; Taponen 
and Pyörälä, 2009; Piessens et al., 2011; Sampimon et al., 2011).

At present, the CNS group comprises 51 species and 25 subspecies (LPSN, 2015). In routine mastitis diagnostic laboratories, CNS are usually not identified to the species level but are reported as a single group (Taponen et al., 2012). Consequently, limited knowledge is available regarding the epidemiology, pathogenicity, and relative importance of different species in this group. Research emanating primarily from European countries has suggested that some of the CNS species recovered from IMI are specifically adapted to the udder, whereas other species are environmental opportunists that only sporadically cause infections (Taponen, 2008; Thorberg et al., 2009; Piessens et al., 2011). Accurate identification of CNS is paramount in order for the epidemiology of the different species to be elucidated and appropriate control strategies to be implemented in dairy herds where CNS mastitis is a problem (Sawant et al., 2009). Although the importance of species-level identification of CNS is recognized, the heterogeneity of the species within this group presents challenges in diagnostic laboratories. Biochemical identification of staphylococcal isolates is labor intensive because of the large number of tests required to differentiate the number of species within the genus (Vanderhaeghen et al., 2015). Furthermore, commercial phenotyping systems have been found to have limited accuracy when identifying CNS of veterinary origin, presumably due to the limited number of veterinary isolates incorporated into the databases (Zadoks and Watts, 2009). Matrixassisted laser desorption/ionization time-of-flight mass spectrometry (MALDI-TOF MS) has been used successfully to identify mastitis pathogens (Barreiro et al., 2010; El Behiry et al., 2013); however, the capital costs of the instrumentation limit the use of MALDITOF MS to specialized research facilities (Wieser et al., 2012). Molecular methods, such as PCR and sequencing of housekeeping genes, have been shown to have higher discriminatory power, reproducibility, and typeability than conventional phenotyping methods and are now recommended for the accurate identification of CNS (Zadoks and Watts, 2009). Amplification and sequencing of the tuf gene, which encodes the elongation factor $\mathrm{Tu}$, has been used successfully to differentiate CNS species (Capurro et al., 2009).

Antimicrobials are commonly used for the treatment of cows with IMI or as a preventative measure during the dry-cow period (Sawant et al., 2009). Staphylococcus aureus is intrinsically susceptible to most classes of antimicrobials but has the extraordinary potential to develop, or acquire, resistance to virtually any antimicrobial to which it is exposed (Chambers and
DeLeo, 2009). Many of the genes encoding antimicrobial resistance determinants reside on mobile genetic elements, which can be exchanged between bacteria of the same or different species occupying the same ecological niche (Lindsay and Holden, 2006). This is of great clinical significance, as the transfer of resistance genes can lead to the emergence of more resistant and virulent bacterial strains (Lindsay and Holden, 2006). Although less pathogenic than Staph. aureus, CNS often exhibit greater resistance to antimicrobials and also have a greater tendency to develop multidrug resistance (MDR) (Taponen and Pyörälä, 2009). The CNS are believed to serve as reservoirs of antimicrobial resistance genes, which can transfer and integrate into the genome of Staph. aureus (Otto, 2013; Vitali et al., 2014).

Evaluating the antimicrobial susceptibility of staphylococcal isolates recovered from IMI is important to guide therapeutic treatment of infected animals (Barkema et al., 2006). Moreover, monitoring the antimicrobial resistance of Staphylococcus spp. in animals is important from a public health perspective. The proximity of humans and animals in the dairy environment presents opportunities for the transmission of bacteria between animal and human hosts (JuhászKaszanyitzky et al., 2007). The recent description of livestock-associated methicillin-resistant Staph. aureus (LA-MRSA; Graveland et al., 2011) and Staph. aureus strains harboring a novel methicillin-resistance gene, mecC (García-Álvarez et al., 2011), have renewed public concerns regarding the role of animals, particularly livestock, as a reservoir and source of antimicrobialresistant bacteria, which can infect humans (Fitzgerald, 2012). Both LA-MRSA and Staph. aureus strains harboring the mecC gene have been recovered from bovine milk samples in several studies (Vanderhaeghen et al., 2010; García-Álvarez et al., 2011; Unnerstad et al., 2013). Inasmuch as the zoonotic transfer of bacteria is of concern from a human health perspective, the reverse scenario - the anthroponotic transfer of bacteria from humans to animals - warrants equal consideration (Fitzgerald, 2012). It is therefore important that bacterial populations at the animal-human interface should be monitored.

Antimicrobial-resistant Staph. aureus, particularly methicillin-resistant Staph. aureus (MRSA), represent a significant public health burden in both hospital and community settings worldwide (Chambers and DeLeo, 2009). The treatment options for infected patients are complicated by the fact that MRSA strains are MDR because they carry other resistance genes on the cassette chromosome harboring the mecA gene (Holmes and Zadoks, 2011). Resistance to frontline antimicro- 
bials such as the glycopeptide vancomycin has been documented and the alarming lack of new antimicrobials is a cause of great concern (Pantosti et al., 2007). Significant efforts are therefore aimed at conserving existing antimicrobials by promoting good antimicrobial stewardship in both human healthcare and veterinary medicine (Morley et al., 2005).

The purpose of this research was to investigate the diversity of Staphylococcus spp. responsible for IMI in South African dairy cows and to assess the susceptibility of the different species to antimicrobials commonly used in the veterinary field as well as antimicrobials relevant to human medicine. Concomitantly, individuals working in close contact with the animals were sampled and the diversity and susceptibility profiles of staphylococcal isolates determined and compared with staphylococcal species of animal origin.

\section{MATERIALS AND METHODS}

\section{Sample Collection and Processing}

Ethical clearance for this investigation was obtained from the Animal Ethics Committee, Faculty of Veterinary Science, University of Pretoria (H010-13) and the University of Pretoria, Faculty of Health Sciences Research Ethics Committee (No.295/2013).

KwaZulu-Natal (KZN) is 1 of 9 provinces in the Republic of South Africa. Commercial dairy herds $(\mathrm{n}=9$; identified by the letters A, B, C, E, F, G, I, J, and L), communal animal herds $(\mathrm{n}=2$; collectively identified by the letter $\mathrm{M})$, and agriculture college herds $(\mathrm{n}=2$; identified by the letters $\mathrm{D}$ and $\mathrm{H}$ ) in KZN were recruited to participate in this study through private and state veterinarians in the province. Participation was voluntary. For commercial dairy herds, the sole criterion for inclusion in this study was a history of staphylococcal mastitis. Because of the limited number of agriculture college herds in the province and the limited accessibility to communal animals, no specific selection criteria could be implemented. Herd sizes ranged from 95 to 1,450 (commercial herds), 40 to 50 (agriculture college herds), and 3 to 8 (communal herds). A single sampling was carried out at each site between October 2013 and March 2014.

Milk samples were aseptically collected into sterile sample tubes following cleaning and disinfection of the teat ends and stripping of the first 2 to 3 squirts of milk. At each of the sampling sites, close-contact workers including animal owners, dairy laborers, and veterinary practitioners were approached and asked to participate in the study by providing a self-collected nasal swab (Copan, Brescia, Italy). Following collection, all milk samples and nasal swab specimens were packed on ice and transported to the laboratory.

All milk samples were visually inspected following receipt in the laboratory. Milk samples showing any visual evidence of abnormality, such as the presence of clots, flakes or blood, were classed as clinical. No SCC was performed on clinical samples. All milk samples with a normal appearance were analyzed by flow cytometry using a Somacount instrument (Bentley Instruments, Chaska, MN), and the number of somatic cells per milliliter of sample was determined.

\section{Microbiological Analysis of Milk Samples and Nasal Specimens}

Ten microliters of each milk sample was inoculated onto one quadrant of a Columbia blood agar plate (Oxoid, Basingstoke, UK) supplemented with 5\% ovine blood. Culture plates were incubated (NuAire, Plymouth, MN) at $37^{\circ} \mathrm{C}$ for $48 \mathrm{~h}$. Nasal specimens were transferred to brain heart infusion broth (Oxoid) and incubated at $37^{\circ} \mathrm{C}$ overnight before being streaked onto Columbia blood agar (Oxoid) supplemented with 5\% ovine blood, BBL Columbia nalidixic acid agar (Becton Dickinson, Sparks, MD), and oxacillin-resistance screening agar (Oxoid). All plates were incubated at $37^{\circ} \mathrm{C}$ for $48 \mathrm{~h}$ before being examined for the presence of staphylococcal-like colonies (Quinn et al., 1999). Preliminary testing of staphylococcal isolates included Gram staining and testing for catalase production. All catalase-positive, gram-positive, coccus-shaped bacterial isolates were tentatively identified as Staphylococcus spp. and tested for coagulase production using rabbit plasma (Bio-Rad, Hercules, CA) and for clumping factor using a commercial latex agglutination kit [Pastorex StaphPlus kit, Bio-Rad (Quinn et al., 1999)].

Only staphylococcal isolates recovered from milk samples with an SCC $\geq 200,000$ cells $/ \mathrm{mL}$ were selected for further characterization. Additional selection criteria for CNS included the occurrence of isolates in pure growth and the presence of 5 or more colonies $(\geq 500$ $\mathrm{cfu} / \mathrm{mL}$ of milk) on primary culture. When more than one type of CNS was isolated from different quarters of the same cow, based on phenotypic appearance, both isolates were retained for further testing. With respect to the staphylococcal isolates recovered from human nasal swabs, all Staph. aureus isolates were retained along with representative CNS colonies from each individual. All isolates were stored in 25\% glycerol (Merck, Darmstadt, Germany) at $-80^{\circ} \mathrm{C}$ (NuAire) until required. 


\section{Identification of Staphylococci and Screening for mecA and pvl Genes Using PCR}

One or two bacterial colonies were suspended in $50 \mu \mathrm{L}$ of sterile deionized water. Bacterial DNA was extracted using the DNeasy blood and tissue kit (Qiagen, Hilden, Germany) in accordance with the manufacturer's instructions. All staphylococcal isolates were amplified using a multiplex PCR assay (multiplex 1) to confirm genus identification, to identify Staph. aureus isolates, and to simultaneously screen isolates for the methicillin resistance gene, mecA, and the Panton-Valentine leukocidin encoding gene, $p v l$. Each PCR assay was carried out in a $25-\mu \mathrm{L}$ volume comprising $1 \times \mathrm{PCR}$ buffer (Promega, Madison, WI), $0.3 \mathrm{~m} M$ deoxynucleotide triphosphate mixture (Promega), $3 \mathrm{mM} \mathrm{MgCl} 2$ (Promega), 0.2 $\mu M$ of each primer, 1.5 U of HotStart GoTaq (Promega) and $2 \mu \mathrm{L}$ of DNA extract. Reactions were cycled in a MJ Mini thermocycler (BioRad, Chaska, MN) with the following parameters: initial denaturation $\left(95^{\circ} \mathrm{C}\right.$ for 2 min) followed by 30 cycles of amplification $\left(94^{\circ} \mathrm{C}\right.$ for 45 $\mathrm{s}, 51^{\circ} \mathrm{C}$ for $90 \mathrm{~s}$, and $72^{\circ} \mathrm{C}$ for $90 \mathrm{~s}$ ) and ending with a final extension step at $72^{\circ} \mathrm{C}$ for $10 \mathrm{~min}$. A positive control and negative control (deionized water) was set up with every batch of PCR samples amplified. Details of all oligonucleotide primers and PCR controls are summarized in Table 1. The PCR products were resolved in a $1.5 \%$ agarose gel (SeaKem, Lonza, Rockland, ME), in $1 \times$ Tris-borate-EDTA (TBE) buffer (Melford, Ipswich, UK). Following staining in a $1 \mu \mathrm{g} / \mathrm{mL}$ ethidium bromide solution (BioRad), the PCR products were visualized and documented (UVIPro, Uvitec, Cambridge, UK).

\section{Speciation of CNS Using PCR, MALDI-TOF MS, and tuf Gene Sequencing}

Following genus-specific identification, CNS were identified to the species level using a combination of methods. All test isolates were amplified using 1 of 2 multiplex PCR assays (multiplex 2 and 3) based on the origin of the isolates. Reactions were prepared in 25$\mu \mathrm{L}$ volumes using the Qiagen Multiplex PCR kit and amplified according to the manufacturer's instructions. The PCR products were analyzed as described above with the exception that a $1.8 \%$ agarose gel (SeaKem, Lonza) was used to resolve the PCR amplicons.

With the exception of one bovine CNS isolate that failed to grow, overnight cultures of all isolates were preserved in chromatography-grade ethanol (Merck) and submitted for MALDI-TOF MS analysis (Bruker Daltonics GmbH, Bremen, Germany). Coagulase-negative staphylococcal isolates that could not be identified using the multiplex-PCR assay or MALDI-TOF MS or where discordant species identifications were obtained using the 2 methods were analyzed further using tuf gene sequencing. The tuf gene was amplified according to the method described by Heikens and coworkers (2005), and PCR amplicons were submitted to Inqaba Biotechnical Industries (Pretoria, South Africa) for sequencing. Consensus sequences were analyzed in GenBank and cut-off values for the percentage of identity were adjusted to $\geq 97 \%$ sequence similarity.

\section{Antimicrobial Susceptibility Testing of Staphylococcal Isolates}

The antimicrobial susceptibility of the staphylococcal test isolates to 15 antimicrobials was carried out using the agar disk-diffusion method according to the Clinical and Laboratory Standards Institute (CLSI, 2008). The antibiotics tested (Oxoid) included amoxicillin and clavulanate $(20 \mu \mathrm{g} / 10 \mu \mathrm{g})$, ampicillin $(10 \mu \mathrm{g})$, cefoxitin $(30 \mu \mathrm{g})$, ceftaroline $(30 \mu \mathrm{g})$, cephalothin $(30 \mu \mathrm{g})$, clindamycin $(2 \mu \mathrm{g})$, erythromycin $(15 \mu \mathrm{g})$, gentamicin $(10 \mu \mathrm{g})$, linezolid $(30 \mu \mathrm{g})$, moxifloxacin $(5 \mu \mathrm{g})$, penicillin $(10 \mathrm{U})$, streptomycin $(10 \mu \mathrm{g})$, tetracycline $(30 \mu \mathrm{g})$, and trimethoprim/sulfamethoxazole $(1.25 / 23.75 \mu \mathrm{g})$. The clindamycin and erythromycin disks were placed within $25 \mathrm{~mm}$ of each other on the agar surface to facilitate the detection of inducible clindamycin resistance or the "D-effect" (Fiebelkorn et al., 2003). A control isolate, Staph. aureus ATCC 25923, was tested together with each batch of field isolates to ensure the validity of the test results. The zone measurements for all antimicrobials, with the exception of fusidic acid and streptomycin, were compared with CLSI breakpoints based on data derived from human medicine (CLSI, $2008,2014)$. In the case of fusidic acid, the breakpoint recommended by the European Committee on Antimicrobial Susceptibility Testing (EUCAST, 2014) was used and for streptomycin a breakpoint of $\geq 14 \mathrm{~mm}$ was used as described by Kim and coworkers (2004) and Shittu and Lin (2006). The production of $\beta$-lactamase by Staph. aureus isolates was determined by examining the edge of the zone of inhibition surrounding the penicillin disk. Isolates showing abrupt, heaped edges were recorded as being resistant to penicillin, irrespective of the zone diameter (CLSI, 2014). Beta-lactamase production by CNS isolates was determined using nitrocefin-impregnated sticks (Oxoid) in accordance with the manufacturer's instructions.

Resistance categories were defined based on recommendations made by Schwarz and coworkers (2010). Briefly, isolates showing susceptibility to all classes of antimicrobials tested were termed pansusceptible; isolates showing resistance to 1 or 2 classes or antimicrobials were termed resistant; and isolates showing 


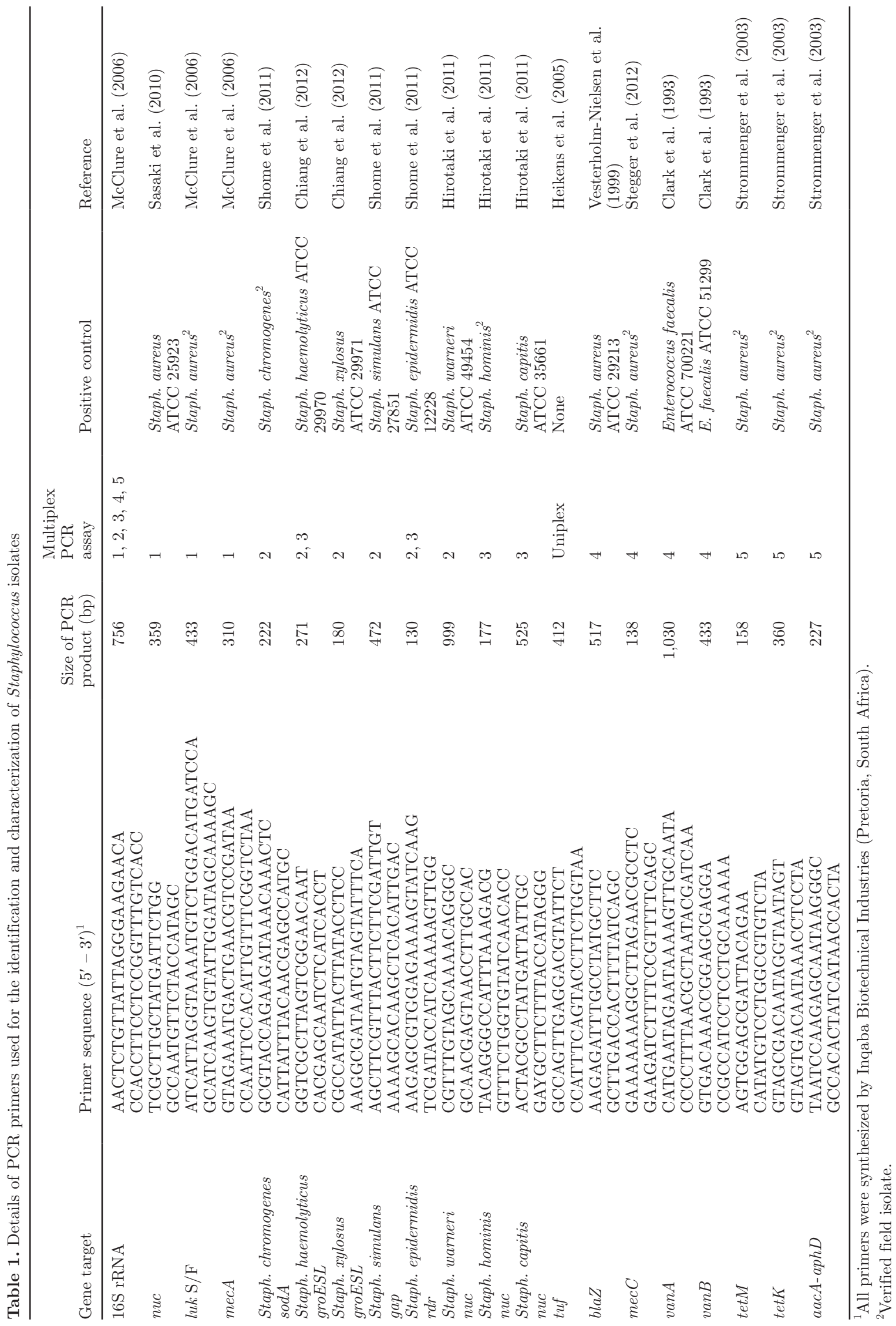


resistance to 3 or more classes of antimicrobials were termed MDR.

\section{PCR Screening of Staphylococcal Isolates for Antimicrobial Resistance Determinants}

Staphylococcal isolates were screened for a combination of 7 antimicrobial resistance genes using 2 multiplex PCR assays. Reactions were prepared in $25-\mu \mathrm{L}$ volumes using the Qiagen Multiplex PCR kit and included primers specific for the blaZ, mecC, vanA, and $\operatorname{van} B$ (multiplex 4 ) and tetK, tet $M$, and $a a c A-a p h D$ (multiplex 5) genes. Amplification of PCR reactions was carried out in a MJ Mini thermocycler (BioRad) using the thermocycling conditions recommended by the kit manufacturer. Electrophoresis was carried out as described above.

\section{RESULTS}

\section{Microbiological Analysis}

A total of 3,387 milk samples from 1,374 cows and 79 human nasal swab specimens were collected from 13 dairy herds. One hundred forty-six Staph. aureus and 102 CNS isolates cultured from the milk samples fulfilled the selection criteria and were retained for further analysis. Staphylococcus aureus was recovered from 12 $(15.2 \%)$ of the human nasal swabs. All 12 Staph. aureus isolates and the $95 \mathrm{CNS}$ isolates recovered from the nasal swabs were retained for analysis.

\section{Identification of Staphylococci and Screening for mecA and pvl Genes by PCR}

All of the analyzed staphylococcal isolates were genotypically identified as Staphylococcus spp. using the first multiplex PCR assay. Furthermore, all of the isolates phenotypically identified as Staph. aureus were confirmed to be Staph. aureus using the same multiplex PCR assay. None of the bovine or human staphylococcal isolates was positive for the Panton-Valentine leucocidin-encoding gene, pvl. Fifteen CNS of human origin tested positive for the mecA gene.

\section{Speciation of CNS Using PCR, MALDI-TOF MS, and tuf Gene Sequencing}

A combination of 2 multiplex PCR assays and MALDI-TOF MS was used to identify the 102 CNS isolates of bovine origin and 95 CNS isolates of human origin. Five bovine isolates originating from 2 farms were not identified using either the multiplex PCR assay or
MALDI-TOF MS and were analyzed further using tuf gene sequencing. The consensus tuf DNA sequences of the 5 isolates showed 99 to100\% agreement with sequences already deposited in GenBank (accession no. EU571021.1). The sequences corresponded to an unidentified Staphylococcus species recovered from bovine mastitis cases deposited by Capurro and coworkers (2009).

A further 9 CNS were analyzed using tuf gene sequencing to confirm the species identification obtained using MALDI-TOF MS. The percentage distribution of CNS species isolated from both the milk samples and human specimens is presented in Table 2. Seven different Staphylococcus spp. were identified among the CNS isolates of bovine origin, with the majority of the isolates being identified as Staph. chromogenes (78.4\%). Other species identified included Staph. xylosus (4.9\%), Staph. hyicus (3.9\%), Staph. simulans (3.9\%), Staph. haemolyticus (1.9\%), Staph. lugdunensis (0.9\%), and Staph. epidermidis (0.9\%). Nine species were identified among the CNS recovered from the human specimens, with Staph. epidermidis (80\%), Staph. chromogenes (6.3\%), and Staph. haemolyticus (5.3\%) predominating.

\section{Antimicrobial Susceptibility Testing of Staphylococcal Isolates}

All staphylococcal isolates were evaluated for susceptibility to antimicrobials used for the treatment of bovine IMI as well as antimicrobials relevant to human medicine. The antimicrobial susceptibility profiles of the Staph. aureus isolates of bovine and human origin are summarized in Table 3. Isolates showing intermediate susceptibility were grouped together with isolates showing resistance to the antimicrobial evaluated.

The Staph. aureus isolates of bovine origin were divided into 8 antibiotypes based on their susceptibility patterns to the different classes of antimicrobials evaluated. Ninety-eight (67.1\%) Staph. aureus isolates of bovine origin were susceptible to all of the antimicrobial classes evaluated (pansusceptible). Thirty-nine $(26.7 \%)$ isolates were resistant to a single class of antimicrobials, whereas $7(4.8 \%)$ were resistant to 2 classes. Two (1.4\%) Staph. aureus isolates, from different herds, exhibited MDR. One of these isolates was resistant to the $\beta$-lactams penicillin and ampicillin, as well as tetracycline and potentiated sulfonamides. The second MDR isolate showed resistance to penicillin and ampicillin, tetracycline, and streptomycin. The Staph. aureus isolates of human origin were divided into 4 antibiotypes. Three $(25 \%)$ of the 12 Staph. aureus isolates were pansusceptible; 4 Staph. aureus isolates (33.3\%) were resistant to a single class of antimicrobials; and 


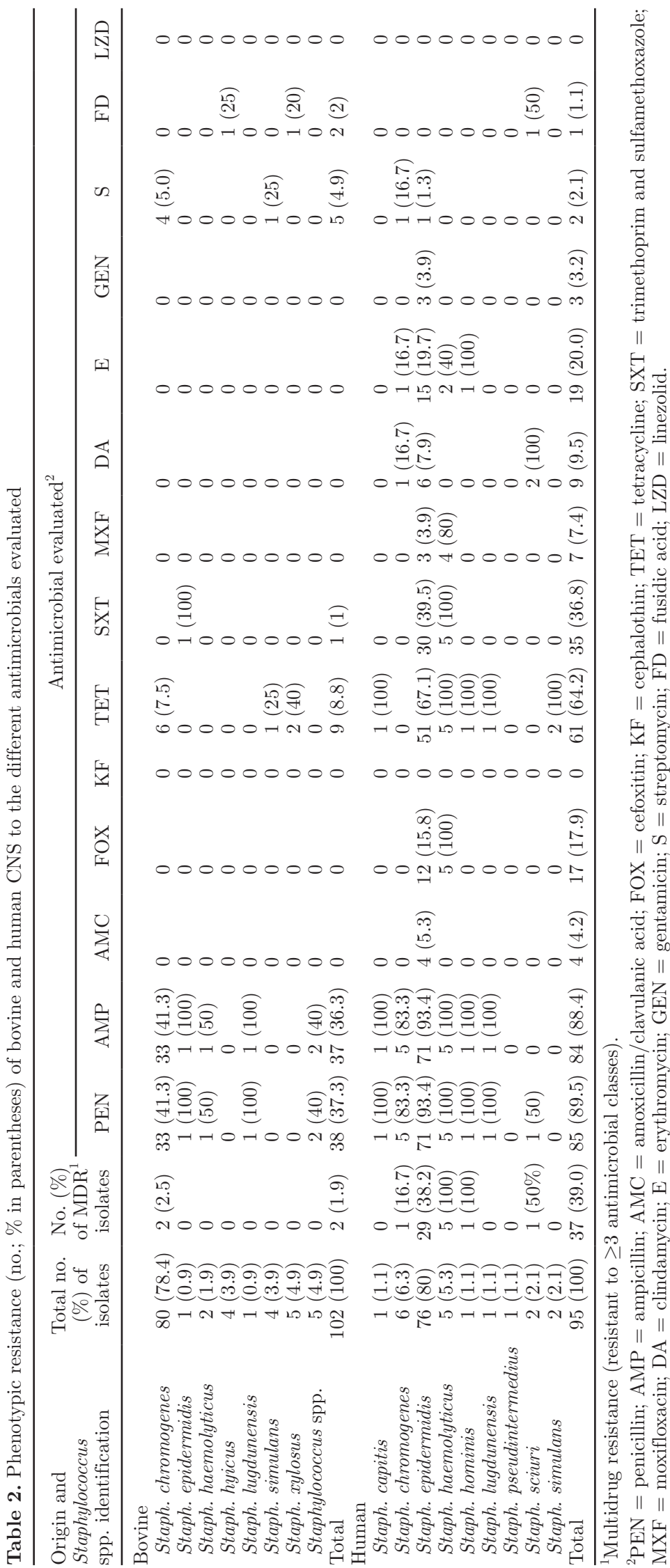




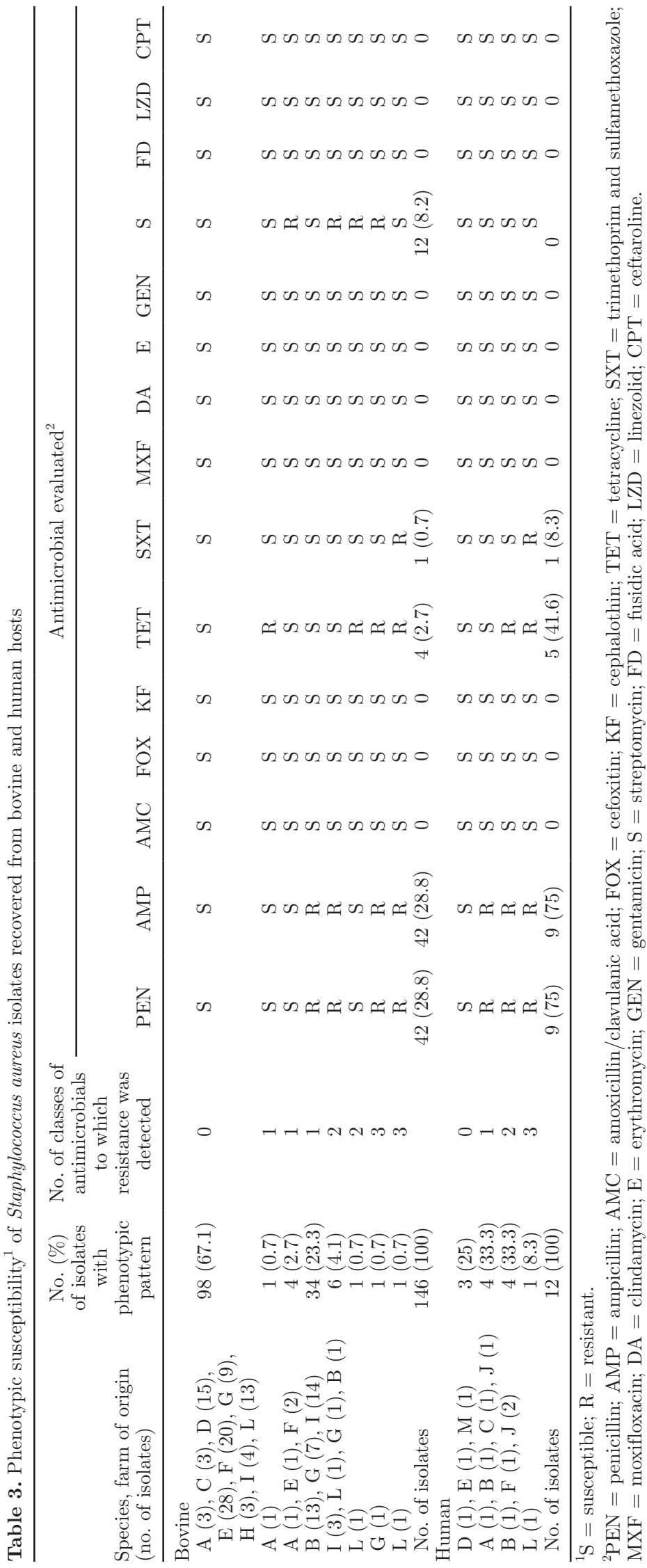


a further 4 isolates $(33.3 \%)$ were resistant to 2 classes of antimicrobials. A single Staph. aureus isolate was found to be MDR, showing resistance to penicillin and ampicillin, as well as tetracycline and the potentiated sulfonamides. None of the Staph. aureus isolates of bovine or human origin showed resistance to cefoxitin (surrogate for methicillin and other penicillinase-resistant $\beta$-lactams), ceftaroline, cephalothin, clindamycin, erythromycin, fusidic acid, gentamicin, linezolid, or moxifloxacin.

The antimicrobial susceptibility of the different CNS species of bovine and human origin are summarized in Tables 2 and 4. Phenotypic resistance to penicillin and ampicillin was observed in $37.3 \%$ of the bovine CNS isolates and $89.5 \%$ of the human CNS isolates. Among the 102 bovine CNS isolates evaluated, only 2 Staph. chromogenes $(1.9 \%)$ isolates showed MDR. None of the bovine CNS isolates showed phenotypic resistance to cefoxitin, cephalothin, clindamycin, erythromycin, gentamicin, linezolid, or moxifloxacin. By comparison, 37 (39\%) of the human CNS isolates were MDR. The resistance profiles of the MDR isolates are detailed in Table 4. None of the CNS isolates of human origin showed phenotypic resistance to cephalothin or linezolid. The 15 human CNS isolates, which tested positive for the presence of the mecA gene using the first multiplex PCR assay and were subsequently identified as Staph. epidermidis $(\mathrm{n}=12)$ and Staph. haemolyticus $(\mathrm{n}=5)$, were found to be phenotypically resistant to cefoxitin.

\section{PCR Screening of Staphylococcal Isolates for Antimicrobial Resistance Determinants}

The bla $Z$ gene was detected in 172 of the 355 (48.5\%) staphylococcal isolates examined. All 172 isolates were found to be resistant to penicillin when tested phenotypically. Two isolates, 1 Staph. sciuri (human origin) and 1 Staph. chromogenes (bovine origin), that were found to be phenotypically resistant to penicillin did not test positive for the bla $Z$ gene using the multiplex PCR assay. None of the staphylococcal isolates tested positive for the presence of the tet $M$ gene. The tetK gene was detected in 76 of $79(96.2 \%)$ isolates that were phenotypically resistant to tetracycline. Three of the staphylococcal isolates that were phenotypically resistant to tetracycline did not carry either the tetK or tetM gene. Nine isolates of human origin (4 Staph. epidermidis, 5 Staph. haemolyticus) tested positive for the presence of the aminoglycoside resistance determinant aacA-aphD. None of the bovine isolates were found to be carrying this specific gene. None of the staphylococcal isolates were positive for the mec $C$ gene or the vancomycin resistance determinants vanA and vanB.

\section{DISCUSSION}

Staphylococci are a common cause of bovine IMI worldwide, including South Africa (Petzer et al., 2009). This study was not designed to carry out a prevalence study but rather to facilitate the collection of a representative number of staphylococcal isolates from different dairy operations in KZN for further characterization. Consequently, the selection of participating commercial dairy herds was based on the criterion that each of the herds had a history of IMI caused by Staphylococcus spp.

A combination of methods was used to identify the CNS isolates of bovine and human origin. This approach was used to improve the accuracy of bacterial identification at the species level. The predominant CNS species recovered from the milk samples analyzed in this study was Staph. chromogenes, which accounted for $78.4 \%$ of the isolates examined. The proportion of different Staphylococcus species recovered from bovine IMI has varied between studies carried out in different countries. In general, Staph. chromogenes, Staph. haemolyticus, Staph. epidermidis, Staph. simulans, and Staph. xylosus are usually among the most commonly isolated species (Vanderhaeghen et al., 2015). In Sweden, Persson-Waller and coworkers (2011) found Staph. chromogenes (24\%) and Staph. epidermidis (22\%) to be the most common CNS species identified among a collection of isolates assembled from 2 national mastitis surveys. A study in Switzerland reported Staph. xylosus (36.0\%) and Staph. chromogenes (16.8\%) to be among the most common CNS causing mastitis (Frey et al., 2013). In the United States, Park and coworkers (2011) identified 11 CNS species from cases of mastitis, with Staph. chromogenes (72.2\%), Staph. xylosus (9.1\%), and Staph. haemolyticus (6.1\%) being the most common species identified. It has been suggested that the distribution of CNS species causing IMI is herd-specific and may be influenced by specific management practices that may vary between countries (Thorberg et al., 2009; Supré et al., 2011). Species-level epidemiological studies conducted in European dairy herds have shown that Staph. chromogenes is a more specific udder pathogen than the other CNS and tends to cause persistent IMI (Supré et al., 2011). Staphylococcus chromogenes was also found to have a significant effect on the SCC of infected quarters, comparable to counts induced by Staph. aureus infections (Supré et al., 2011).

Five of the CNS isolates remained unidentified following PCR, MALDI-TOF MS, and sequencing of the tuf gene. All 5 of the isolates had the same tuf gene sequence and in all likelihood are the same species. The tuf gene sequence showed 99 to $100 \%$ similarity with sequence data deposited by Capurro and cowork- 
PROFILING STAPHYLOCOCCI CAUSING MASTITIS

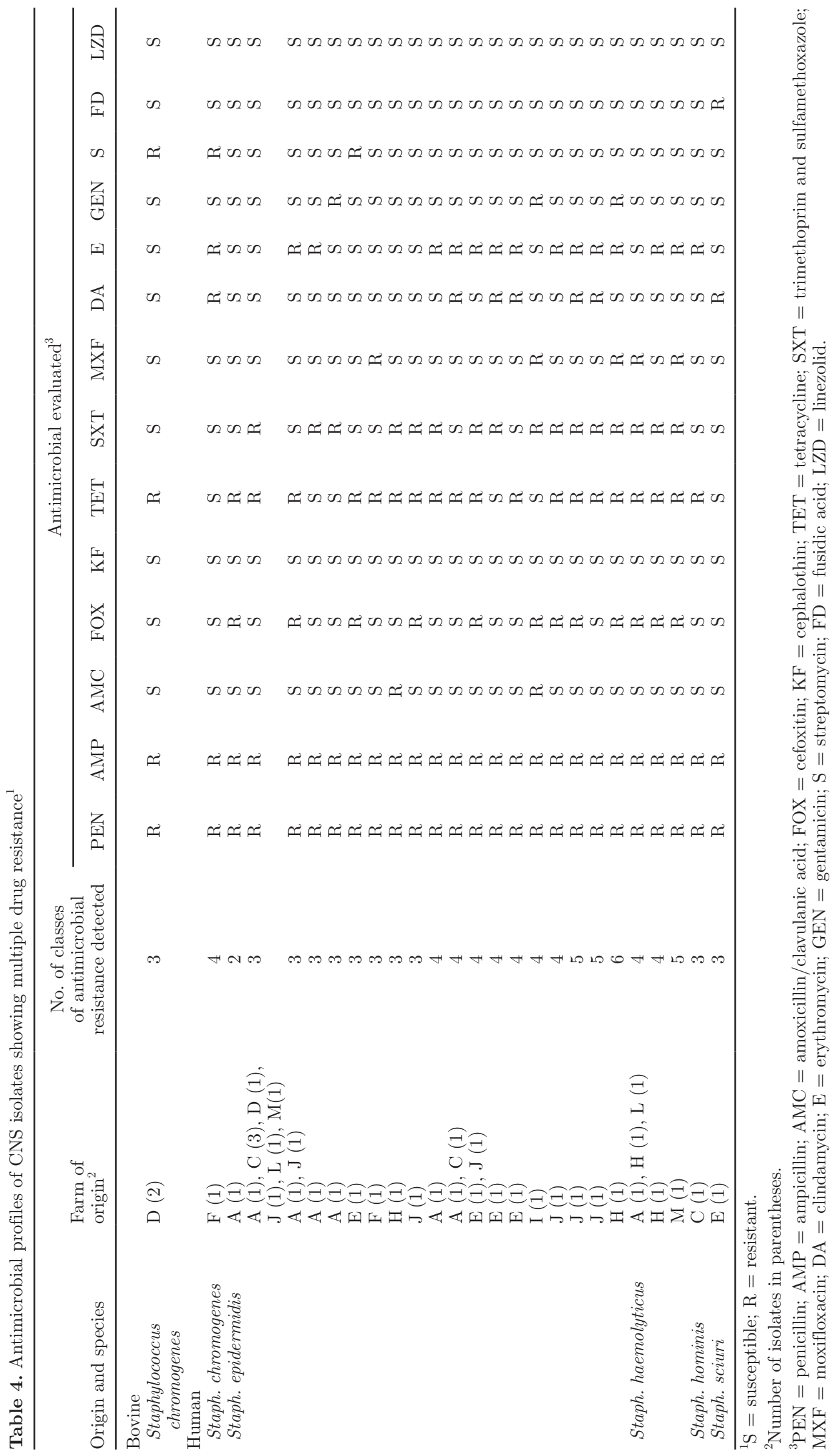

Journal of Dairy Science Vol. 98 No. 9, 2015 
ers (2009), which interestingly belonged to an isolate recovered from mastitic milk samples in Finland. In recent years, several new Staphylococcus species have been described. Supré and coworkers (2010) described a novel Staphylococcus species, Staph. devriesei, which had been isolated from bovine teat apices as well as milk from study herds in Belgium and the Netherlands. Taponen and coworkers (2012) published details describing a new, previously unidentified Staphylococcus species, named Staph. agnetis. Isolates representing this newly described species were recovered from bovine milk samples (Taponen et al., 2012). Further genotyping studies will be undertaken to identify the unidentified Staphylococcus spp. recovered from the milk samples analyzed in the current study.

The predominant CNS recovered from the human nasal swab samples was Staph. epidermidis. This is not surprising as Staph. epidermidis is a known commensal forming part of the natural microflora on human skin (Thorberg et al., 2006). Molecular typing studies conducted by Thorberg and coworkers (2006) in Sweden showed that Staph. epidermidis isolates recovered from cases of mastitis were genotypically identical to those recovered from the skin of milkers. This observation led them to suggest that Staph. epidermidis is a zoonotic organism. In contrast to the high prevalence of Staph. epidermidis in the human swab samples analyzed in the current study, only one of the bovine isolates tested was identified as Staph. epidermidis. This may indicate that Staph. epidermidis is not a significant causative agent of IMI in our study area.

Overall, $15.2 \%$ of the humans sampled in this study were found to harbor Staph. aureus. It is reported that approximately $20 \%$ of healthy human individuals are persistent carriers of Staph. aureus, 30\% are intermittent carriers, and $50 \%$ of individuals are never colonized by Staph. aureus (Kluytmans and Struelans, 2009; Graveland et al., 2011). Nasal carriage of Staph. aureus is recognized as a risk factor for acquiring infections and additionally plays a role in the dissemination of Staph. aureus in hospitals and the community (Zriouil et al., 2012).

The $\beta$-lactam antibiotics penicillin and ampicillin are used extensively for the prevention and treatment of IMI in dairy cows (IVS, 2015). In South Africa, more than half of the intramammary preparations available for use comprise penicillin or ampicillin with or without dihydrostreptomycin (IVS, 2015). Furthermore, many of the preparations are available to farmers over the counter, making it difficult to monitor and control antimicrobial usage. In our study, resistance to penicillin was the most commonly detected resistance, with $28.8 \%$ of Staph. aureus and $37.3 \%$ of CNS isolates showing phenotypic resistance to penicillin. This scenario paral- lels reports from other countries. Pyörälä and coworkers (2011) indicated that generally between one-third and two-thirds of bovine Staph. aureus isolates are resistant to penicillin, with lower percentages being reported in countries where strict antimicrobial policies have been implemented. Differences in the levels of bacterial resistance documented between studies are influenced by sampling strategies and bacterial populations but also by differences in test methodology and the use of different interpretation criteria (Barkema et al., 2006). It is therefore suggested that comparisons between studies be restricted to studies that have used the same methodology and interpretation criteria (Schwarz et al., 2010).

It is of great significance, from both an animal and a public health perspective, that none of the staphylococcal isolates of bovine origin exhibited resistance to cefoxitin, the in vitro surrogate for examining the phenotypic susceptibility of isolates to methicillin (CLSI, 2014). Several studies have reported on the presence of methicillin-resistant staphylococci in milk samples, raising concerns over milk as a source of methicillinresistant bacteria. In Switzerland, $47 \%$ of the CNS isolates evaluated in vitro were found to be resistant to oxacillin (Frey et al., 2013). Vanderhaeghen and coworkers (2010) found that almost $10 \%$ of herds sampled in Belgium to have cases of mastitis caused by MRSA. The in-herd prevalence of MRSA varied between 0 and $7.4 \%$. Furthermore, all strains had characteristics typical of the zoonotic LA-MRSA strains belonging to clonal complex (CC) 398.

In South Africa, antimicrobial susceptibility data are sparse. Three studies have reported on the occurrence of MRSA from cases of bovine mastitis with prevalence rates varying between 1.1 and $93.2 \%$ (Petzer et al., 2007; Ateba et al., 2010; Schmidt, 2011). The high prevalence of $93.2 \%$ noted in one study is largely attributable to the sampling approach and the small sample size (Ateba et al., 2010). None of the studies confirmed the presence of the mecA gene in the isolates exhibiting phenotypic resistance. Generally, it is accepted that screening for mecA is the most reliable method for the detection of methicillin resistance in staphylococcal isolates. Performing only phenotypic tests has previously led to the reporting of both false-positive and false-negative results (Vanderhaeghen et al., 2010).

Phenotypic resistance to antimicrobials other than penicillin and ampicillin was not common among the bovine staphylococcal isolates evaluated in our study. A low percentage of Staph. aureus (8.2\%) and CNS (4.9\%) isolates exhibited phenotypic resistance to streptomycin. Resistance to tetracycline was also noted, with $2.7 \%$ of the Staph. aureus and $8.8 \%$ of the CNS isolates showing phenotypic resistance to this antimicrobial. 
The observed resistance coincides with the availability of both of these antimicrobials in intramammary preparations in South Africa (IVS, 2015). None of the bovine Staph. aureus or CNS isolates exhibited resistance to cephalothin, clindamycin, erythromycin, linezolid, or moxifloxacin, and only 2 isolates, 1 Staph. hyicus and 1 Staph. xylosus, were found to be phenotypically resistant to fusidic acid. The aforementioned antimicrobials have limited application in veterinary medicine but are used in human medicine to treat different types of staphylococcal infections (Lowy, 2013).

Multidrug resistance was more common among the CNS than the Staph. aureus isolates and more common among human isolates than bovine isolates. In total, 37 $(39 \%)$ of the CNS isolates of human origin were MDR, whereas only 2 Staph. chromogenes isolates of bovine origin were MDR. Two Staph. aureus isolates of bovine origin were MDR, whereas only a single Staph. aureus isolate from the human nasal swabs was found to be MDR. Interestingly, the human MDR Staph. aureus was isolated from a farm laborer on the same farm as the MDR bovine Staph. aureus isolate and displayed the same antimicrobial susceptibility profile. Future genotyping studies will be undertaken to determine the genetic relatedness of the bovine and human isolates and investigate possible bacterial transmission between hosts.

Antimicrobial susceptibility testing of isolates was supplemented by screening for specific antimicrobial resistance genes. None of the staphylococcal isolates evaluated were shown to carry the $\operatorname{van} A$ and $\operatorname{van} B$ genes, which confer vancomycin resistance to isolates. Considering the importance and reliance on vancomycin for the treatment of MRSA infections in human medicine, the lack of vancomycin resistance markers in both the bovine and human staphylococci analyzed in our study is therefore positive.

The correlation between the phenotypic susceptibility of isolates to penicillin with the presence of the blaZ gene was not absolute. A Staph. sciuri isolate of human origin and a Staph. chromogenes isolate of bovine origin were found to be phenotypically resistant to penicillin but negative for the presence of the bla $Z$ gene. A possible explanation for this discrepancy could be a mutation of the primer-annealing site that prevented amplification. All staphylococcal test isolates were also screened for the presence of 2 tetracycline resistance determinants: tet $K$ and tet $M$. The tet $K$ gene was detected in the majority of the isolates showing phenotypic resistance to tetracycline, whereas tet $M$ was not detected. Three isolates, 2 Staph. chromogenes and 1 Staph. haemolyticus, that were phenotypically resistant to tetracycline tested negative for the presence of both tetK and tetM. This discrepancy could be due to the presence of other tetracyclin-resistance encoding genes, such as tet $L$ or tet $O$, or due to a mutation in the primer-annealing site. The discrepancies observed between the phenotypic susceptibility of our test isolates and PCR screening for resistance genes highlight some of the shortcomings associated with the molecular detection of antimicrobial resistance. In many cases, antimicrobial resistance can be mediated by several different genes and mechanisms, some of which are still undescribed (Fluit et al., 2001).

One of the specific limitations associated with the determination of the antimicrobial susceptibility of veterinary bacterial isolates is the fact that there are currently very few antimicrobial breakpoints validated specifically for use with isolates of veterinary origin (Schwarz et al., 2010). At present, interpretive data are only available for the testing of mastitis pathogens against ceftiofur, penicillin-novobiocin, and pirlimycin (CLSI, 2008). The latter antimicrobial is currently not registered for use in South Africa (IVS, 2015). Because of the lack of data, it is common practice to make use of breakpoints derived from human medicine to interpret in vitro data. This is not ideal and should be considered when interpreting results.

\section{CONCLUSIONS}

This study provides insight into the diversity of Staphylococcus spp. causing IMI in cows in South African dairy herds and communal animals. The predominance of $S$. chromogenes among the CNS isolates warrants further investigation to elucidate the epidemiology and virulence characteristics of strains circulating within herds. This study further demonstrated that antimicrobial resistance among Staphylococcus spp. causing IMI was generally low. These results suggest the responsible usage of antimicrobials on dairy farms or the existence of management practices that do not favor the accumulation of resistance genes, or both. Because of the propensity of staphylococci to acquire antimicrobial resistance through the genetic exchange of DNA with compatible strains occupying the same microbiological niche, continued monitoring of bacterial populations is necessary.

\section{ACKNOWLEDGMENTS}

The authors thank the University of Pretoria, RESCOM, the National Research Foundation (NRF) of South Africa, and the KZN Department of Agriculture \& Rural Development (South Africa) for financially supporting this work. The MALDI-TOF MS work is based on the research supported in part by the NRF of South Africa (Grant UID 74426). Finally, the authors extend their thanks and appreciation to S. Monecke 
(Institute for Medical Microbiology and Hygiene, TU Dresden, Dresden, Germany) for his kind contribution of Staph. aureus control cultures.

\section{REFERENCES}

Akineden, Ö., C. Annemüller, A. Hassan, C. Lämmler, W. Wolter, and M. Zschöck. 2001. Toxin genes and other characteristics of Staphylococcus aureus isolates from milk of cows with mastitis. Clin. Diagn. Lab. Immunol. 8:959-964.

Ateba, C. N., M. Mbewe, M. S. Moneoang, and C. C. Bezuidenhout. 2010. Antibiotic-resistant Staphylococcus aureus isolated from milk in the Mafikeng area, North West Province, South Africa. S. Afr. J. Sci. 106. http://dx.doi.org/10.4102/sajs.v106i11/12.243.

Barkema, H. W., Y. H. Schukken, and R. N. Zadoks. 2006. Invited review: The role of cow, pathogen, and treatment regimen in the therapeutic success of bovine Staphylococcus aureus mastitis. J. Dairy Sci. 89:1877-1895.

Barreiro, J. R., C. R. Ferreira, G. B. Sanvido, M. Kostrzewa, T. Maier, B. Wegemann, V. Böttcher, M. N. Eberlin, and M. V. dos Santos. 2010. Short communication: Identification of subclinical cow mastitis pathogens in milk by matrix-assisted laser desorption/ionization time-of-flight mass spectrometry. J. Dairy Sci. 93:5661-5667.

Capurro, A., K. Artursson, K. Persson Waller, B. Bengtsson, H. Ericsson-Unnerstad, and A. Aspán. 2009. Comparison of a commercialized phenotyping system, antimicrobial susceptibility testing, and tuf gene sequenced-based genotyping for species-level identification of coagulase-negative staphylococci isolated from cases of bovine mastitis. Vet. Microbiol. 134:327-333.

Chambers, H. F., and F. R. DeLeo. 2009. Waves of resistance: Staphylococcus aureus in the antibiotic era. Nat. Rev. Microbiol. 7:629641.

Chiang, Y.-C., H.-C. Lu, S.-C. Li, Y.-H. Chang, H.-Y. Chen, C.-W. Lin, and H.-Y. Tsen. 2012. Development of PCR primers and a DNA macroarray for the simultaneous detection of major Staphylococcus species using groESL gene. Foodborne Pathog. Dis. 9:249-257.

Clark, N. C., R. C. Cooksey, B. C. Hill, J. M. Swenson, and F. C. Tenover. 1993. Characterization of glycopeptide-resistant enterococci from U.S. hospitals. Antimicrob. Agents Chemother. 37:2311-2317.

CLSI (Clinical Laboratory Standards Institute). 2008. Performance Standards for Antimicrobial Disk and Dilution Susceptibility Tests for Bacteria Isolated From Animals-Third Edition: Vol. 28, No. 8. Approved Standard M31-A3. Clinical Laboratory Standards Institute, Wayne, PA.

CLSI (Clinical Laboratory Standards Institute). 2014. Performance Standards for Antimicrobial Susceptibility Testing: Twenty-fourth International Supplement. CLSI document M100-S24: Vol. 34, No. 1. Clinical Laboratory Standards Institute, Wayne, PA.

El Behiry, A., R. M. Zahran, E. Marzouk, and M. Al-Dabib. 2013. Phenotypical and mass spectral assessment methods for identification of some contagious mastitis pathogens. Am. J. Microbiol. 4:32-41.

EUCAST (European Committee on Antimicrobial Susceptibility Testing). 2014. Breakpoint tables for the interpretation of MICs and zone diameters. Version 4.0, 2014. http://www.eucast.org.

Fiebelkorn, K. R., S. A. Crawford, M. L. McElmeel, and J. H. Jorgensen. 2003. Practical disk diffusion method for detection of inducible clindamycin resistance in Staphylococcus aureus and coagulase-negative staphylococci. J. Clin. Microbiol. 41:4740-4744.

Fitzgerald, J. R. 2012. Livestock-associated Staphylococcus aureus: Origin, evolution and public health threat. Trends Microbiol. 20:192-198. http://dx.doi.org/10.1016/j.tim.2012.01.006.

Fluit, A. C., M. R. Visser, and F.-J. Schmitz. 2001. Molecular detection of antimicrobial resistance. Clin. Microbiol. Rev. 14:836-871.

Frey, Y., J. P. Rodriguez, A. Thomann, S. Schwendener, and V. Perreten. 2013. Genetic characterization of antimicrobial resistance in coagulase-negative staphylococci from bovine mastitis milk. J. Dairy Sci. 96:2247-2257.
García-Álvarez, L., M. Holden, H. Lindsay, C. Webb, D. Brown, M. Curran, E. Walpole, K. Brooks, D. Pickard, C. Teale, J. Parkhill, S. Bentley, G. Edwards, E. Girvan, A. Kearns, B. Pichon, R. Hill, A. Larsen, R. Skov, S. Peacock, D. Maskell, and M. Holmes. 2011. Methicillin-resistant Staphylococcus aureus with a novel mecA homologue in human and bovine populations in the UK and Denmark: A descriptive study. Lancet Infect. Dis. 11:595-603.

Gentilini, E., G. Denamiel, P. Llorente, S. Godaly, M. Rebuelto, and O. DeGregorio. 2000. Antimicrobial susceptibility of Staphylococcus aureus isolated from bovine mastitis in Argentina. J. Dairy Sci. 83:1224-1227.

Graveland, H., B. Duim, E. van Duijkeren, D. Heederik, and J. Wagenaar. 2011. Livestock-associated methicillin-resistant Staphylococcus aureus in animals and humans. Int. J. Med. Microbiol. 301:630-634.

Heikens, E., A. Fleer, A. Paauw, A. Florijn, and A. Fluit. 2005. Comparison of genotypic and phenotypic methods for species-level identification of clinical isolates of coagulase-negative staphylococci. J. Clin. Microbiol. 43:2286-2290.

Hirotaki, S., T. Sasaki, K. Kuwahara-Arai, and K. Hiramatsu. 2011. Rapid and accurate identification of human-associated staphylococci by use of multiplex PCR. J. Clin. Microbiol. 49:3627-3631.

Holmes, M. A., and R. N. Zadoks. 2011. Methicillin resistant S. aureus in human and bovine mastitis. J. Mammary Gland Biol. Neoplasia 16:373-382.

IVS. 2015. Index of Veterinary Specialities. Vol 53. Hirt and Carter, Durba, South Africa.

Juhász-Kaszanyitzky, É., S. Jánosi, P. Somogyi, Á. Dán, L. van der Graaf-van Bloois, E. van Duijkeren, and J. Wagenaar. 2007. MRSA transmission between cows and humans. Emerg. Infect. Dis. 13:630-632.

Kim, H. B., H.-C. Jang, H. J. Nam, Y. S. Lee, B. S. Kim, W. B. Park, K. D. Lee, Y. J. Choi, S. W. Park, M. D. Oh, E.-C. Kim, and K. W. Choe. 2004. In vitro activities of 28 antimicrobial agents against Staphylococcus aureus isolates from tertiary-care hospitals in Korea: A nationwide survey. Antimicrob. Agents Chemother. $48: 1124-1127$

Kluytmans, J., and M. Struelans. 2009. Methicillin-resistant Staphylococcus aureus in the hospital. BMJ 338:b364.

Lindsay, J. A., and M. T. G. Holden. 2006. Understanding the rise of the superbug: Investigation of the evolution and genomic variation of Staphylococcus aureus. Funct. Integr. Genomics 6:186-201.

Lowy, F. 2013. Staphylococcal infections. Pages 159-170 in Harrison's Principles of Internal Medicine. 18th ed. D. L. Longo, A. S. Fauci, D. L., Kasper, S. L. Hauser, J. J. Jameson, and J. Loscalzo, ed. McGraw-Hill, New York, NY.

LPSN. 2015. List of Prokaryotic Names with Standing in Nomenclature. Accessed Apr. 8, 2015. http://www.bacterio.net/staphylococcus. html.

McClure, J.-A., J. M. Conly, V. Lau, S. Elsayed, T. Louie, W. Hutchins, and K. Zhang. 2006. Novel Multiplex PCR assay for detection of staphylococcal virulence marker Panton-Valentine leukocidin genes and simultaneous discrimination of methicillin-susceptible from -resistant staphylococci. J. Clin. Microbiol. 44:1141-1144.

Morley, P. S., M. D. Apley, T. E. Besser, D. P. Burney, P. J. FedorkaCray, M. G. Papich, J. L. Traub-Dargatz, and J. S. Weese. 2005. Antimicrobial drug use in veterinary medicine. J. Vet. Intern. Med. 19:617-629.

Otto, M. 2013. Coagulase-negative staphylococci as reservoirs of genes facilitating MRSA infection. BioEssays 35:4-11.

Pantosti, A., A. Sanchini, and M. Monaco. 2007. Mechanisms of antibiotic resistance in Staphylococcus aureus. Future Microbiol. $2: 323-334$.

Park, J.-Y., L. K. Fox, K. S. Seo, M. A. McGuire, Y. H. Park, F. R. Rurangirwa, W. M. Sischo, and G. A. Bohach. 2011. Comparison of phenotypic and genotypic methods for the species identification of coagulase-negative staphylococcal isolates from bovine intramammary infections. Vet. Microbiol. 147:142-148.

Persson Waller, K., A. Aspán, A. Nyman, Y. Persson, and U. G. Andersson. 2011. CNS species and antimicrobial resistance in clinical and subclinical bovine mastitis. Vet. Microbiol. 152:112-116. 
Petzer, I.-M., J. Karzis, T. J. van der Schans, J. C. Watermeyer, and M. Smither. 2007. Antibiotic efficacy against staphylococcal udder pathogens in dairy cows in South Africa from 2000 to 2006. Pages 33-49. Livestock Health and Production Group of the South African Veterinary Association Congress. Vetlink, Pretoria, South Africa.

Petzer, I.-M., J. Karzis, J. Watermeyer, T. J. van der Schans, and R. van Reenen. 2009. Trends in udder health and emerging mastitogenic pathogens in South African dairy herds. J. S. Afr. Vet. Assoc. 80:17-22.

Piessens, V., E. van Coillie, B. Verbist, K. Supre, G. Braem, A. van Nuffel, and L. de Vuyst. 2011. Distribution of coagulase-negative Staphylococcus species from milk and environment of dairy cows differs between herds. J. Dairy Sci. 94:2933-2944.

Pyörälä, S., H. Simojoki, and S. Taponen. 2011. News about mastitis-causing staphylococci. European Buiatrics Forum, Marseille, France.

Quinn, P. J., M. E. Carter, B. Markey, and G. R. Carter. 1999. Staphylococcus species. Pages 118-126 in Clinical Veterinary Microbiology. Mosby, Madrid, Spain.

Sampimon, O. C., T. Lam, D. Mevius, Y. Schukken, and R. Zadoks. 2011. Antimicrobial susceptibility of coagulase-negative staphylococci isolated from bovine milk samples. Vet. Microbiol. 150:173179 .

Sasaki, T., S. Tsubakishita, Y. Tanaka, A. Sakusabe, M. Ohtsuka, S Hirotaki, T. Kawakami, T. Fukata, and K. Hiramatsu. 2010. Multiplex-PCR method for species identification of coagulase-positive staphylococci. J. Clin. Microbiol. 48:765-769.

Sawant, A. A., B. E. Gillespie, and S. Oliver. 2009. Antimicrobial susceptibility of coagulase-negative Staphylococcus species isolated from bovine milk. Vet. Microbiol. 134:73-81.

Schmidt, T. 2011. In vitro antimicrobial susceptibility of Staphylococcus aureus strains from dairy herds in KwaZulu-Natal. J. S. Afr. Vet. Assoc. 82:76-79.

Schwarz, S., P. Silley, S. Simjee, N. Woodford, E. van Duijkeren, A. Johnson, and W. Gaastra. 2010. Editorial: Assessing the antimicrobial susceptibility of bacteria obtained from animals. J. Antimicrob. Chemother. 65:601-604.

Shittu, A. O., and J. Lin. 2006. Antimicrobial susceptibility patterns and characterization of clinical isolates of Staphylococcus aureus in KwaZulu-Natal province, South Africa. BMC Infect. Dis. 6:125.

Shome, B. R., S. Das Mitra, M. Bhuvana, N. Krithiga, D. Velu, R. Shome, S. Isloor, S. B. Barbuddhe, and H. Rahman. 2011. Multiplex PCR assay for species identification of bovine mastitis pathogens. J. Appl. Microbiol. 111:1349-1356.

Stegger, M., P. Anderson, A. Kearns, B. Pichon, M. Holmes, G. Edwards, F. Laurent, C. Teale, R. Skov, and A. Larsen. 2012. Rapid detection, differentiation and typing of methicillin-resistant Staphylococcus aureus harbouring either mecA or the new mecA homologue mecA $A_{L A A 251}$. Clin. Microbiol. Infect. 18:395-400.

Strommenger, B., C. Kettlitz, G. Werner, and W. Witte. 2003. Multiplex PCR assay for simultaneous detection of nine clinically relevant antibiotic resistance genes in Staphylococcus aureus. J. Clin. Microbiol. 41:4089-4094.

Supré, K., S. De Vliegher, I. Cleenwerck, K. Engelbeen, S. Van Trappen, S. Piepers, O. S. Sampimon, R. N. Zadoks, P. De Vos, and F. Haesebrouck. 2010. Staphylococcus devriesei sp. nov., isolated from teat apices and milk of dairy cows. Int. J. Syst. Evol. Microbiol. 60:2739-2744.

Supré, K., F. Haesebrouck, R. N. Zadoks, M. Vaneechoutte, S. Piepers, and S. De Vliegher. 2011. Some coagulase-negative Staphylococ- cus species affect udder health more than others. J. Dairy Sci 94:2329-2340.

Taponen, S. 2008. Bovine mastitis caused by coagulase-negative staphylococci. Doctoral Diss. Univ. Helsinki, Helsinki, Finland.

Taponen, S., and S. Pyörälä. 2009. Coagulase-negative staphylococci as cause of bovine mastitis - not so different from Staphylococcus aureus? Vet. Microbiol. 134:29-36.

Taponen, S., K. Supré, V. Piessens, E. Van Coillie, S. De Vliegher, and J. M. K. Koort. 2012. Staphylococcus agnetis sp. nov., a coagulasevariable species from bovine subclinical and mild clinical mastitis. Int. J. Syst. Evol. Microbiol. 62:61-65.

Tenhagen, B. A., G. Koster, J. Wallmann, and W. Heuwieser. 2006 Prevalence of mastitis pathogens and their resistance against antimicrobial agents in dairy cows in Brandenburg, Germany. J. Dairy Sci. 89:2542-2551.

Thorberg, B. M., M. L. Danielsson-Tham, U. Emanuelson, and K. Persson Waller. 2009. Bovine subclinical mastitis caused by different types of coagulase-negative staphylococci. J. Dairy Sci. 92:4962-4970.

Thorberg, B. M., I. Kühn, F. Aarestrup, B. Brändström, P. Jonsson, and M.-L. Danielsson-Tham. 2006. Pheno- and genotyping of Staphylococcus epidermidis isolated from bovine milk and human skin. Vet. Microbiol. 115:163-172.

Unnerstad, H. E., B. Bengtsson, M. Horn af Rantzien, and S. Börjesson. 2013. Methicillin-resistant Staphylococcus aureus containing $m e c C$ in Swedish dairy cows. Acta Vet. Scand. 55:6 http://dx.doi. org/10.1186/1751-0147-55-6.

Vanderhaeghen, W., T. Cerpentier, C. Adriaensen, J. Vicca, K. Hermans, and P. Butaye. 2010. Methicillin-resistant Staphylococcus aureus (MRSA) ST398 associated with clinical and subclinical mastitis in Belgian cows. Vet. Microbiol. 144:166-171.

Vanderhaeghen, W., S. Piepers, F. Leroy, E. Van Coillie, F. Haesebrouck, and S. De Vliegher. 2015. Identification, typing, ecology and epidemiology of coagulase negative staphylococci associated with ruminants. Vet. J. 203:44-51. http://dx.doi.org/10.1016/j. tvjl.2014.11.001.

Vesterholm-Nielsen, M., M. Larsen, J. Olsen, and F. Aarestrup. 1999 Occurrence of the blaZ gene in penicillin resistant Staphylococcus aureus isolated from bovine mastitis in Denmark. Acta Vet. Scand. 40:279-286.

Vitali, L. A., D. Petrelli, A. Lamikanra, M. Prenna, and E. O. Akinkunmi. 2014. Diversity of antibiotic resistance genes and staphylococcal cassette chromosome mec elements in faecal isolates of coagulase-negative staphylococci from Nigeria. BMC Microbiol. 14:106.

Wieser, A.. L. Schneider, J. Jung, and S. Schubert. 2012. MALDITOF MS in microbiological diagnostics-Identification of microorganisms and beyond (mini review). Appl. Microbiol. Biotechnol. 93:965-974.

Zadoks, R. N., W. B. van Leeuwen, D. Kreft, L. K. Fox, H. W. Barkema, Y. H. Schukken, and A. van Belkum. 2002. Comparison of Staphylococcus aureus from bovine and human skin, milking equipment, and bovine milk by phage typing, pulsed-field gel electrophoresis, and binary typing. J. Clin. Microbiol. 40:3894-3902.

Zadoks, R. N., and J. L. Watts. 2009. Species identification of coagulase-negative staphylococci: Genotyping is superior to phenotyping. Vet. Microbiol. 134:20-28.

Zriouil, S. B., M. Bekkali, and K. Zerouali. 2012. Epidemiology of Staphylococcus aureus infections and nasal carriage at the Ibn Rochd University hospital center, Casablanca, Morocco. Braz. J. Infect. Dis. 16:279-283. 